\section{Die Röntgendiagnose}

\section{Der Mach-Effekt}

A. J. M. van den Belt

Fachgruppe für Veterinär-Radiologie der Universität Utrecht

\section{Anamnese}

Niederländische Warmblutstute, 1 Jahr. Am linken Metakarpus befindet sich dorsodistal seit 12 Tagen eine perforierende Verletzung. Anfangs war bis auf den Knochen zu sondieren.
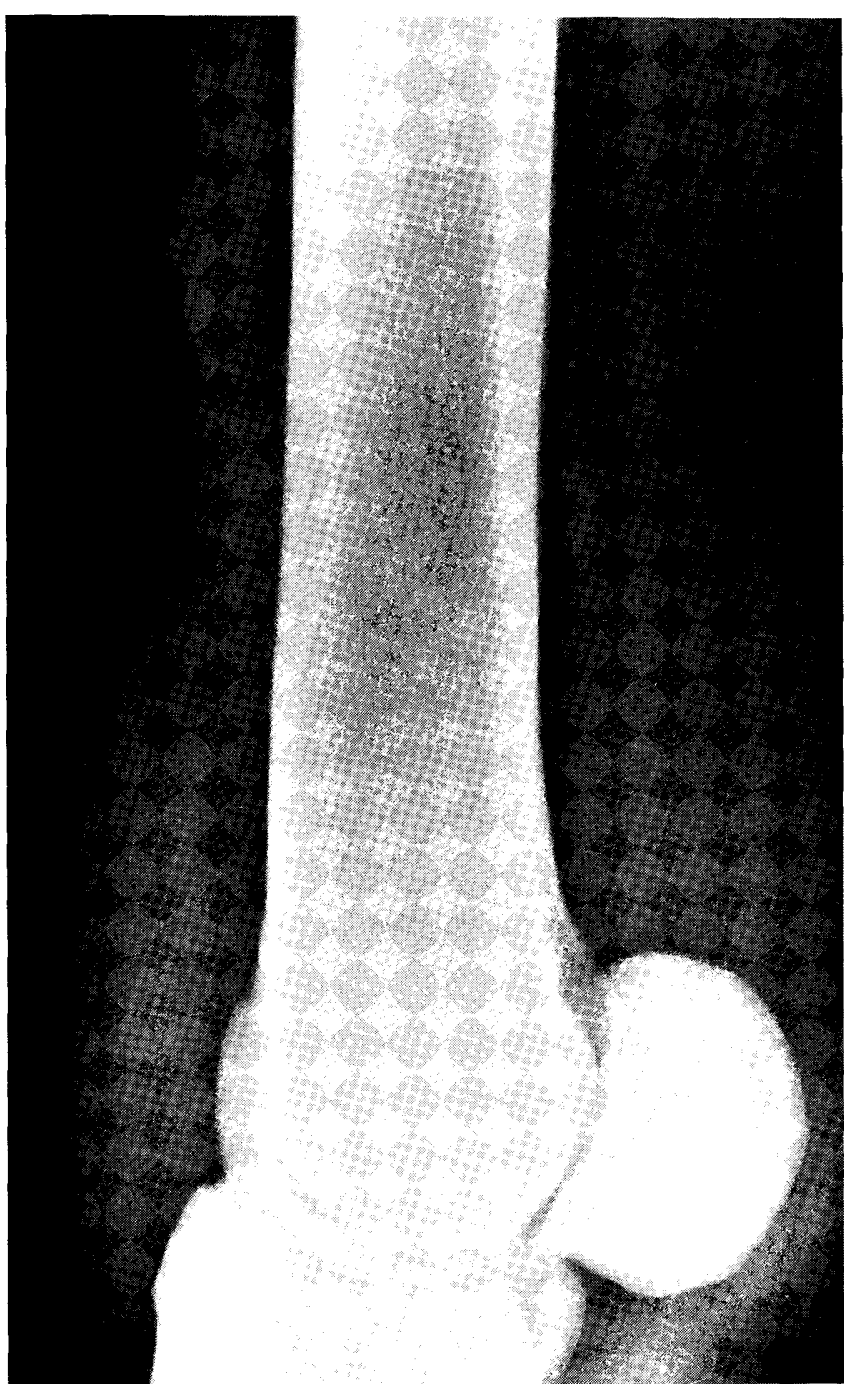

Abb. 1: Lateromediale Aufnahme des linken Metakarpus

\section{Röntgenbefund}

Abb. 1 stellt die lateromediale Aufnahme des linken Metakarpus dar. Im Bereich der Verletzung ist eine umfangreiche Weichteilverschattung sichtbar. Im korrespondierenden Teil der dorsalen Kortikalis des Metakarpus ist eine verschwommene, nicht scharf begrenzte und deshalb als frisch sowie noch aktiv zu beurteilende periostale Knochenzubildung zu erkennen. An derselben Stelle fällt eine linienförmige Aufhellung auf.

Abb. 2 zeigt die gleiche Aufnahmeebene 2 Wochen später. Die periostale Knochenzubildung erscheint dicker, dichter, weniger aktiv, und der Rand ist deutlich abgesetzt. Die Weichteilschwellung ist noch sichtbar, deren Struktur ist jedoch dichter und unregelmäßiger geworden. Die linienförmige Aufhellung ist nicht mehr zu sehen.

\section{Kommentar}

Eine linienförmige Aufhellung im Bereich der Kortikalis in
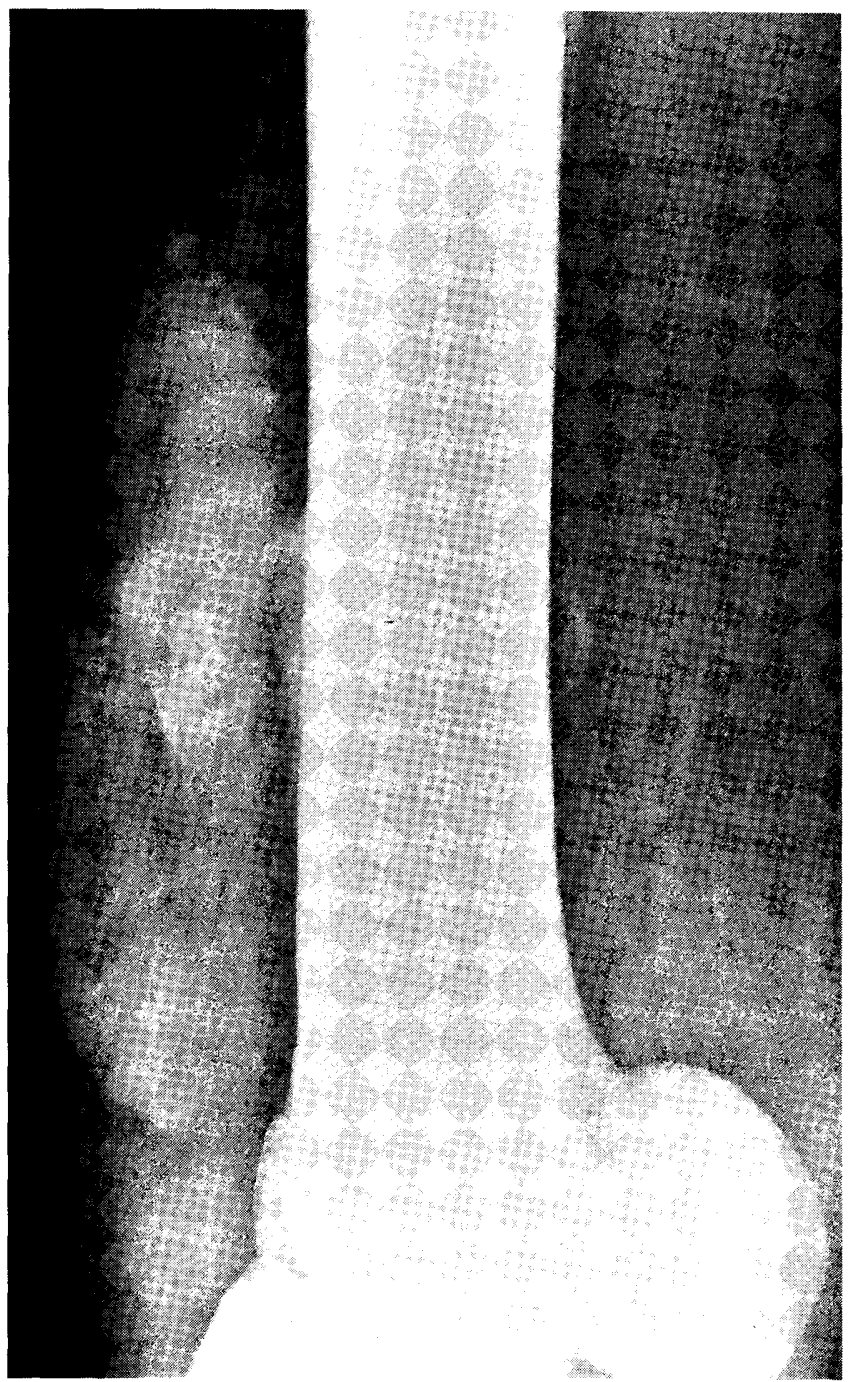

Abb. 2: Die gleiche Aufnahme 2 Wochen später 
Zusammenhang mit einer periostalen Knochenzubildung ist entweder als erste röntgenologisch sichtbare Veränderung im Verlauf einer Knochensequesterbildung oder aber als sogenannte Mach-Täuschung zu deuten. Im Falle einer

\section{Literatur}

Dik, K. J. (1979): Sequesters bij het paard. Tijdschr. Diergeneesk., 104 Dik, K.J. (1979): Traumatische periostale botnieuwvorming bij het paard. Tijdschr. Diergeneesk., 104

Dik, K. J., und Gunsser, I. (1987): Atlas der Röntgendiagnostik beim Pferd, Band 1: Erkrankungen im Bereich der Vorderextremität. Schlütersche, Hannover, 124-131

Koppel, E. (1983): Lamelläre Sequestration an den Röhrenknochen des Pferdes. Wien tierärztl. Mschr. 70, 128-130
Sequestration sollte sich die linienförmige Aufhellung nach 2 Wochen deutlicher darstellen. Das Fehlen der entsprechenden Linie auf der zweiten Aufnahme deutet auf eine Mach-Täuschung bei dem ersten Röntgenbild hin.
Moons, U., Verschooten, F., de Moor, A., und Wouters, L. (1980): Bone Sequestrations Consequence of Limb Wounds in the Horse. Radiology 21. $40-44$

\section{Dr. A. J. M. van den Belt}

Fachgruppe für Veterinär-Radiologie

Reichsuniversität Utrecht

Yalelaan 10

NL-Utrecht 2506

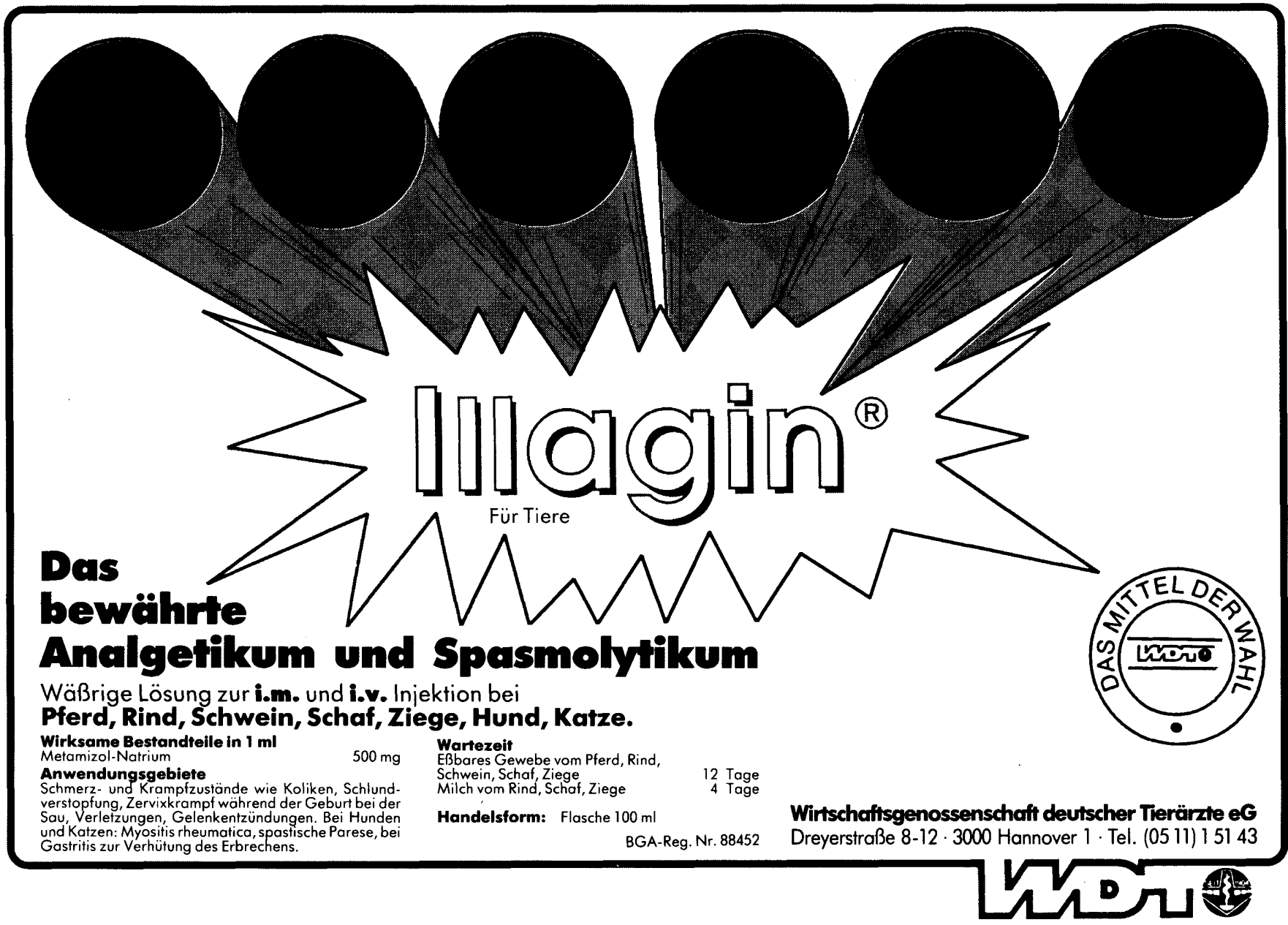

